\title{
THE IMPACT OF ONLINE EDUCATION ON THE STUDENT'S SUCCESS IN THE COURSE "TEACHING GEOMETRY IN PRIMARY EDUCATION"
}

\author{
Katarína Žilková ${ }^{1}$ \& Alexandra Kondeková ${ }^{2}$ \\ ${ }^{1}$ Comenius University in Bratislava \\ Račianska 59, 81334 Bratislava, Slovakia \\ ${ }^{2}$ Masaryk University in Brno \\ Žerotínovo nám. 617/9, 60177 Brno, Czech Republic \\ ${ }^{1}$ zilkova@fedu.uniba.sk, ORCID 0000-0002-7561-7385 \\ 2alexandra.kondekova@gmail.com, ORCID 0000-0003-0397-1462
}

\begin{abstract}
During the COVID-19 pandemic (since March 2020) the Faculty of Education at Comenius University in Bratislava immediately switched to distance learning. A part of the university online education was e-testing using the Moodle system. Lecturers had to change their standard approaches, including the introduction of online testing to their teaching. We were interested in the effect of online learning and e-testing on the level of students' knowledge gained in the course "Teaching geometry in primary education". The goal of the study was to investigate the impact of e-learning on knowledge of students of preprimary and primary education. We analyzed the students' results between 2018 and 2021 to compare the traditional teaching and testing in the paper-pencil-compass and ruler form (standard group of students) with the online form of teaching and testing (COVID group of students). Statistical methods of quantitative research were used to analyze the data separately for full-time and part-time students. The statistical analysis showed that there are no differences between the distributions of the percentage scores of standard and COVID group of full-time students. The same result was obtained for the distributions of percentage scores for standard and COVID group of part-time students. Hence, the online form of teaching and testing was equivalent to the in-person form. In addition to the percentage score of students, it is also necessary to investigate other determinants of online education and their impact on the preparation of future primary education teachers.
\end{abstract}

Keywords: online education, distance learning, online testing, preservice primary teachers. 


\section{INTRODUCTION}

The pandemic caused by the spread of the COVID-19 resulted in rapid transitions from in-person to remote learning across the world. In Slovakia, universities immediately reacted to the novel situation and transitioned from in-person to online learning within few weeks. However, over time it turned out, that the universities were not well prepared for such a prompt transition. Therefore, the lecturers had to make great effort to be able to teach online and to create electronic study materials of different types, including online tests, in a short amount of time (e.g. evaluation of the survey on distance teaching in WS 2020/2021 - teachers; evaluation of the survey on distance teaching in WS 2020/2021 - students, CIT UK, 2021). However, the real impact of these transitions from in-person to online learning on students' remains unclear.

Overall, there are two contrasting views prevailing within literature on the impact of online learning on the students. While some authors believe students can greatly benefit from e-learning, others suggest it can have an adverse impact on students' wellbeing. Although, online education can be as effective as in-person education (Pokorný, 2021a, 2021b). Yadav (2021) found that the pandemic had a significant impact on students' mental and physical wellbeing. More specifically, Yadav (2021) revealed that the screen time during remote learning had an adverse impact on physical health of the students as many of them developed eye problems due to prolonged screen time. Moreover, an increased number of students were found to have mental issues during pandemic in comparison to the pre-pandemic time. Expanding previous findings, Chakraborty, Mittal, Gupta, Yadav, \& Arora (2020) revealed that university students found the online education extremely stressful, and they felt that it had a considerable impact on their overall health and social life. Furthermore, Žilková, \& Žilková (2021) found that university students perceived online education and etesting to be more stressful than in-person learning. Overall, this suggests that the pandemic had a great impact on students' overall wellbeing.

However, some authors (e.g. Spitzer \& Musslick, 2021) believe that students can greatly benefit from online learning. More specifically, Spitzer \& Musslick (2021) found, that the gap in performance between low- and high- achieving students narrowed during the pandemic. In other words, the authors found that low-achieving students showed greater improvement in performance in comparison to the highachieving students. They concluded that "online learning environments may be effective in preventing educational losses associated with current and future shutdowns of schools" (Spitzer \& Musslick, 2021). For example, Oproiu (2015) suggested that online education contributes to students' development of autonomy. In fact, Oproiu (2015) claimed that learning autonomy in online learning can be achieved by using blended learning via Moodle. This is essential as recent studies found that increased autonomy in students leads to lower mathematical anxiety (Kuruc et al., 2020). Chiu (2021) revealed that providing students with digital support for remote learning supports their autonomy, competence, and relatedness. Based on self-determination theory, satisfying students' psychological needs further increases students' motivation to engage in online learning. On the whole, it appears that while e-learning can 
potentially have an adverse effect on students' overall wellbeing, this effect can be reduced by using sufficient support.

\section{ONLINE LEARNING IN THE COURSE "TEACHING GEOMETRY IN PRIMARY EDUCATION"}

Overall, lecturers at the Comenius University (CU) in Bratislava were aware of the potential limitations of online learning. Thus, a great effort was made to reduce the potential negative effects of online learning on the students when implementing online learning. At the Comenius university we generally used LMS Moodle and Office 365 (especially MS Teams) as base tools for education throughout the pandemic. More specifically, MS Teams was the platform for online education (e.g. lectures, consultations), LMS Moodle was the platform for sharing educational materials (e.g. texts, audio and videos, assignments, and e-testing) for students. Before the pandemic, we used Moodle mainly as a supporting environment, thus it served as an environment to blended learning.

The course "Teaching geometry in primary education" at the Faculty of Education is intended for future teachers of mathematics in primary education. The course has two main goals: to develop students' geometric thinking and to prepare students for teaching elementary geometry. Teaching geometry requires gaining theoretical knowledge as well as practical skills to solve geometrical problems and tasks. During our online education, we used various geometrical manipulatives (e.g. physical cubes or mirrors or paper folding - we used them via video camera and MS Teams) and software products (e. g. dynamic geometry system GeoGebra or our own geometrical applets retrieved from www.delmat.info). Another manipulative activities and geometric algorithms were replaced using of different software tools (e.g. e-whiteboard). Although, traditional geometry teaching significantly differs from the online teaching we believe that students can greatly benefit from both approaches to teaching.

We developed an e-course for future primary teachers named 'Teaching geometry in primary education'. The aim of this course was to aid the development of theoretical knowledge and practical skills in future primary teachers. It was important that the future primary teachers learned that they could teach geometry in-person as well as remotely. We were interested to see how the online development of the theoretical knowledge and practical skills in future primary teachers impacted their academic results. Thus, we compared the results of the students who were taught remotely with the results of the students from previous years who were taught and tested in a standard manner. Because it was not possible to use the standard approach to testing (i.e., paper-pencil-compass-ruler tests) during the pandemic, we created Moodle tests to examine students' knowledge. 


\section{RESEARCH}

\subsection{Methods of data collection, research tools}

The Faculty of Education at Comenius University in Bratislava shifted to distance learning in March 2020. Therefore, the mathematical courses focusing on teaching geometry in primary education were delivered remotely. For online teaching we used the MS Teams platform which enabled the geometry lecturer to share their screen with the students. As we mentioned above, we used GeoGebra and other interactive geometry environments, for example applets. Such teaching was supported by selfstudy materials that were uploaded on Moodle.

During semester we examined students' knowledge by giving them two specific tests. While one test was focused on plane geometry the other one was focused on spatial geometry. Although, students usually take the paper-pencil test in which they are allowed to use compass and ruler, this was not possible due to the pandemic. Thus, it was necessary to create e-tests. We decided to perform student examination via Moodle. The content of the online test resembled the content of the traditional paper-pencil tests.

To simplify the test evaluation on Moodle, we decided to reformulate some test tasks. We used single or multiple-choice questions, dropdown questions or dichotomous (yes/no; true/false) questions, etc., to a great extent. We based formulations of distractors on our experience from previous years and presented the most common incorrect student answers. Some examples of test tasks are shown in Table 1.

Table 1. Sample tasks in a Moodle e-test

\begin{tabular}{|c|c|c|c|}
\hline Topic/task type & \multicolumn{3}{|c|}{ Task in Moodle } \\
\hline $\begin{array}{l}\text { Sorting of } \\
\text { polygons } \\
\text { task type: } \\
\text { dropdown } \\
\text { questions }\end{array}$ & \multicolumn{3}{|c|}{$\begin{array}{l}\text { Decide as precis } \\
\text { Shape A is ... } \\
\text { Shape B is ... } \\
\text { Shape C is ... }\end{array}$} \\
\hline $\begin{array}{l}\text { Basic and } \\
\text { derived } \\
\text { geometric terms } \\
\text { task type: } \\
\text { dichotomous } \\
\text { questions (true/ } \\
\text { false) }\end{array}$ & \multicolumn{3}{|c|}{$\begin{array}{l}\text { Let there be line segment KL. Point P belongs to line segment KL. } \\
\text { Point } \mathrm{M} \text { belongs to line KL and does not belong to segment KL. } \\
\text { Point } \mathrm{N} \text { lies behind M, so that point M lies on the ray PL. Find the } \\
\text { truth value of statements: } \\
\text { - Point } \mathrm{L} \text { lies between points PN and L does not lie between MN. } \\
\text { - Point L lies on the line PM and on ray PK } \\
\text { - Point P lies on half-line KL or on ray LK }\end{array}$} \\
\hline \multirow{3}{*}{$\begin{array}{l}\text { Mutual position } \\
\text { of lines in space } \\
\text { task type: } \\
\text { dropdown } \\
\text { questions }\end{array}$} & \multirow{3}{*}{\multicolumn{2}{|c|}{$\begin{array}{l}\text { Line HD is skew to line } \\
\text { Line LF is parallel to line } \\
\text { Line GH is intersecting to line }\end{array}$}} & \\
\hline & & & \\
\hline & & & \\
\hline
\end{tabular}


Basic and derived geometric terms task type: multiple-choice question
Let there be line p. Points A, B, C, D lie on the line so that point B lies between points $\mathrm{A}$ and $\mathrm{C}$ and point $\mathrm{A}$ lies between points $\mathrm{B}$ and D. Choose which statements are false:

Choose one or more answers:

a) Half-line $\mathrm{BD}$ and half-line $\mathrm{BA}$ are identical half-lines

b) The intersection of $A D$ and $A C$ is point $A$

c) The union of half-lines BC and AD is line $p$

d) Half-lines BC and BD are opposite
Spatial

imagination building from cubes

Task type: fill by dragging to the image
Create the plan of building

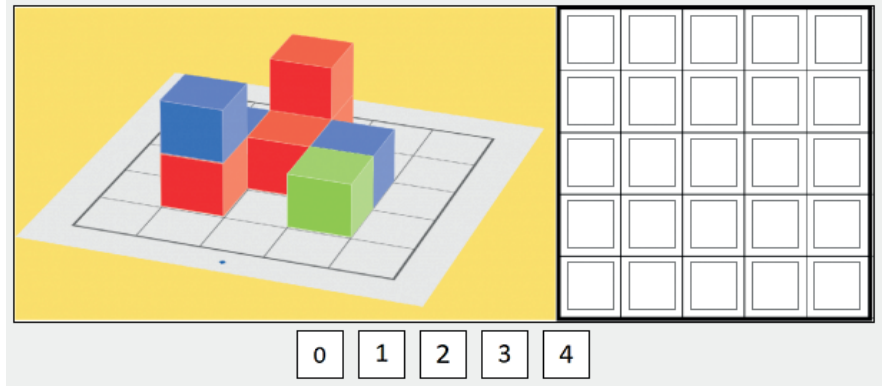

$3 D$ shapes and their attributes task type: short number answer

How many?

a) regular polyhedrons

b) prisms

c) cuboids

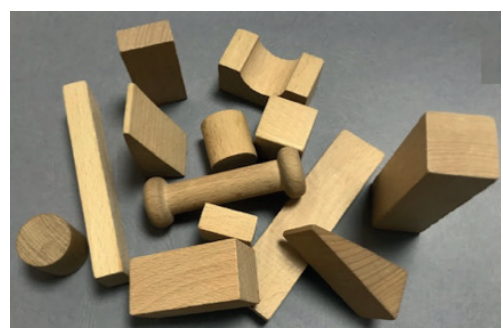

polygons and their measuring task type: short number answer

Calculate

a) the area of the polygon

b) perimeter of the polygon

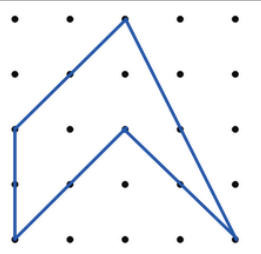

Source: Own work.

\subsection{Objectives of the research}

Overall, we attempted to create an e-test that would be an equivalent to a traditional test with regard to its content and difficulty level. Thus, the purpose of this study was to investigate whether there were any differences in student scores on the traditional testing compared to the e-testing. We were also interested in whether the results were influenced by the distance learning mode.

Q1: What effect has online education and e-testing on the results of students of the course "Teaching geometry in primary education" in comparison to the traditional education and traditional paper-pencil-ruler tests? 


\subsection{Research design}

The research sample consisted of the students who took the course "Teaching geometry in primary education" between 2018 and 2021. Each student was taught by the same lecturer. Both full-time students and part-time students were included in the study, however, they were analysed separately as we believe that different form of the study may play a role in the ability to adapt to online teaching and testing. Full-time and part-time students were further split into two groups based on the way of teaching and testing in the semester when they attended the course. Hence, the students from summer semesters 2018 and 2019, when there was no pandemic and the standard way of teaching and testing took place, formed control (standard) group. Students from summer semesters 2020, 2021 and winter semester 2020 formed the COVID group when the teaching and testing was done online. We collected students' scores from two compulsory tests written during the semester which contributed to their final grade. We calculated percentage scores of students obtained as the sum of their total scores divided by the sum of maximum possible score. The analysis was performed on the percentage scores rather than the total scores as the total scores differed in standard and COVID semesters due to different formulation of the tasks in the online space. We assume the independence between the control groups and COVID groups as the results of the students are independent. Although, we are not able to find out the differences between the baseline knowledge of students enrolled in the course in standard or COVID semesters, we may assume it is the same. This assumption is based on our teaching experience and the fact that there were no changes in accreditation of the study programme, conditions of admission to the faculty or enrollment in the course. For all tests we use the significance level $\alpha=0.05$.

\subsection{Results and discussion}

\subsubsection{Full-time students}

At first, the analysis was performed on the percentage scores of the full-time students. The basic characteristics of the data is displayed in Table 2, where $\mathrm{n}$ denotes the number of full-time students in given groups. We see that the sample size (n) for the COVID group is higher than for the standard group. The mean percentage scores and the medians are very similar in both groups indicating symmetric distributions within the groups. The standard deviations are relatively alike in both groups.

Table 2. Characteristics of the data for full-time students

\begin{tabular}{ccccc}
\hline Pandemic situation & n & Mean & Median & Standard deviation \\
\hline standard & 91 & 0.731 & 0.736 & 0.134 \\
COVID & 129 & 0.708 & 0.709 & 0.146 \\
\hline
\end{tabular}

Source: Own work.

The observations made about the distributions of the data from Table 2 are also supported by a boxplot (Figure 1). The box is constructed from the $25 \%$ and $75 \%$ quartiles, the middle line shows the median percentage score, the mean is illustrated 
with the red dot. There are no outlying values in the percentage scores of full-time students. The same lengths of the whiskers at both ends of both boxes suggest again symmetrical distributions of percentage scores in both groups.

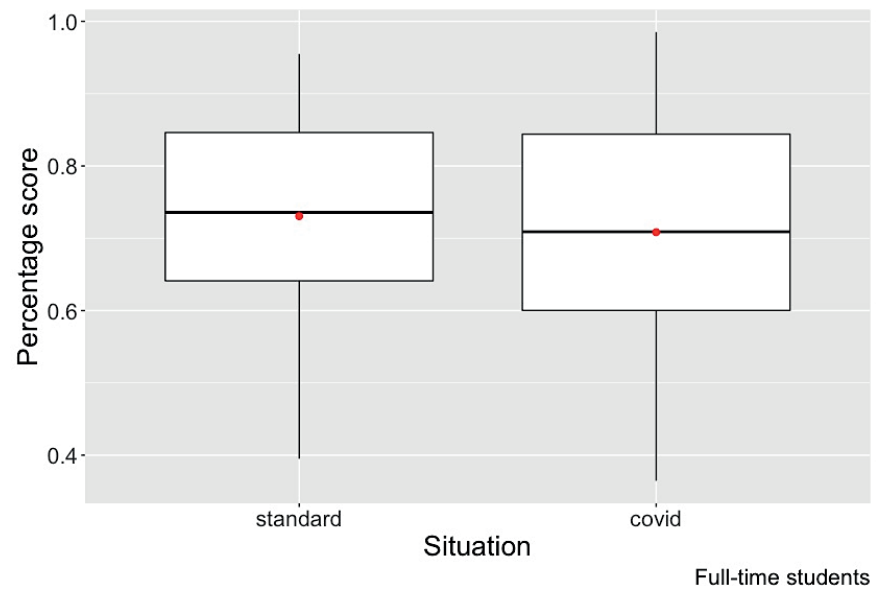

F ig u r e 1. The boxplots of the percentage score of full-time students

Source: Own work.

In Table 2 we observed that both the mean and the median are slightly higher for the standard group. The aim of the analysis is to use hypotheses testing to find out whether the observed difference between the groups is statistically significant. First, we tested for normality in the groups as the boxplots indicate symmetrical distribution. We test for normality using Shapiro-Wilk test, which is chosen from the tests of normality because of relatively small sample sizes in the groups. The null hypothesis about the normality of the percentage scores was rejected at the significance level 0.05 in both groups ( $\mathrm{p}$-value for standard group 0.017, $\mathrm{p}$-value for COVID group 0.030 ). Hence, the percentage scores of students are not normally distributed on the significance level 0.05 and we have to use non-parametric test instead of parametric test. Based on the literature review we were not able to assume anything about the underlying distributions, thus, we chose the two-sample Kolmogorov-Smirnov test in order to test for any differences in the distributions. Because there are contrasting views in the literature regarding the effect of online learning on students' performances, we used the two-sided alternative. We test the null hypothesis that there is no difference between the standard and COVID group against the alternative that there is a difference. The value of the test statistics is $\mathrm{D}=0.150$ and the corresponding p-value 0.180 , thus the null hypothesis about the equality of the distributions of standard and COVID group was not rejected at the significance level 0.05. Therefore, there is not a significant difference between the distribution of percentage scores of the group of full-time students who were taught and tested face-to-face and the group of full-time students who were taught and tested online. 


\subsubsection{Part-time students}

The same analysis was performed on the percentage scores of part-time students. The basic characteristics of the two groups of part-time students is displayed in Table 3. The number of students in both groups is this time approximately the same. The median values and the mean values were a bit different, mainly in the standard group. The mean value was greater for the COVID group, and the median was also slightly higher for the COVID group. The standard deviation was slightly higher for the standard group. These characteristics suggest that the distribution of the percentage scores for the standard group of part-time students is left-skewed.

Tab le 3. Characteristics of the data for part-time students

\begin{tabular}{ccccc}
\hline Pandemic situation & $\mathbf{n}$ & Mean & Median & Standard deviation \\
\hline standard & 50 & 0.635 & 0.700 & 0.194 \\
COVID & 46 & 0.717 & 0.732 & 0.161 \\
\hline
\end{tabular}

Source: Own work.

We used a boxplot (see Figure 2) to illustrate the distributions of the percentage scores for both groups of part-time students. In both groups there was a low percentage score marked as an outlier from the distribution. The distribution in the standard group might be also heavy-tailed and it seemed to differ from the distribution of the percentage scores in COVID group.

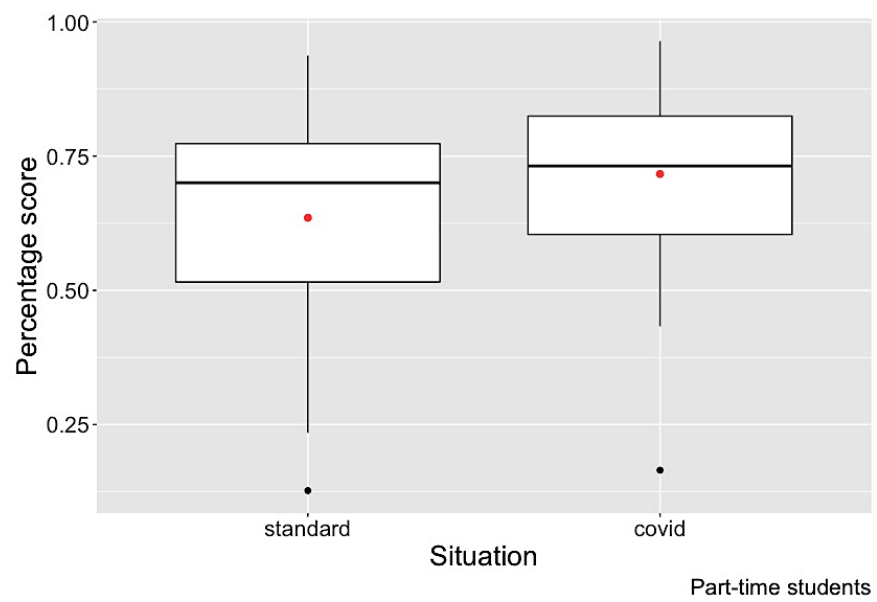

F ig u r e 2. The boxplots of the percentage score of part-time students

Source: Own work.

The observations about distributions are confirmed by the Shapiro-Wilk test of normality. This test rejects the null hypothesis about the normality of the data in both groups ( $p$-value for standard group 0.006, $p$-value for COVID group 0.032). The underlying distributions are unknown. Hence, we again used the non-parametric 
two-sample Kolmogorov-Smirnov test with two-sided alternative to find out whether the differences in the distributions suspected in the characteristics of the groups in Table 3 and visible in the boxplots in Figure 2 are statistically significant. We test the null hypothesis that the distributions of data are equal in the standard and COVID group against the alternative that there is a difference between the distributions. The value of the test statistics was $\mathrm{D}=0.255$ and the corresponding $\mathrm{p}$-value was 0.09 . Thus, the null hypothesis about the equality of the distributions of percentage scores of part-time students in the standard and COVID groups was not rejected at the significance level 0.05 . Thus, the differences in the distributions of the data were not statistically significant.

In general, we found that the percentage scores of both full-time and part-time students in standard and COVID groups were not normally distributed and that the distribution of the percentage score might be considered equal for those two groups at the significance level 0.05 . These results suggest that both the online form of teaching and the online form of testing do not have any impact on the students' performance in the course "Teaching geometry in primary education". Thus, we may conclude that the online version of the test is a good alternative to the paper test and the teaching form was well adjusted to the online environment. At the same time, we realise the limitations of our research which was conducted on a small sample size and some of the assumptions had to be made without testing them. First of all, the independence of the percentage scores of students might be violated as we included students from several years and they could share the tasks from the tests. Also, we assumed the same baseline knowledge of the students which should be formally tested and further research needs to be done taking this into consideration. The biggest limitation is the online form of testing itself. There is no possibility of guaranteeing the same conditions of writing the test online as in the class. We are not able to fully ensure that the students do not help each other or have any other means of help during the test although they are fully monitored via MS Teams. Also, the tests themselves needed to be modified in order to be used online and provided more possibilities of guessing the correct answer (multiple choice and dichotomous questions, drop-down selection).

\section{CONCLUSION}

E-learning and e-testing became a key part of the distance learning at universities during the COVID-19 pandemic, thus also at the Comenius University in Bratislava. Distance learning of the course "Teaching geometry in primary education" at the Faculty of Pedagogics was conducted via MS Teams and students could also use study materials on Moodle. While teaching online, we presented activities with real manipulatives using video camera in MS Teams environment and also virtual manipulatives in the interactive applet environment (www.delmat.info). Additional geometric situations were modelled with the help of the dynamic geometry software GeoGebra. E-testing was done in Moodle. We investigated the impact of the e-learning and e-testing forms on the students' results in the course "Teaching geometry in primary education" and compared them with the results (percentage scores) of students from previous years. We found no statistically significant differences between 
the distributions of the percentage scores of groups of students enrolled in the course before the pandemic situation and the group of students taught and tested online due to COVID situation. These results were obtained for the full-time students as well as for the part-time students. Therefore, we showed that the online version of the test was a good alternative to the paper test and the teaching form was well adjusted to the online environment, so the e-learning and e-testing were equivalent to the standard form of education. Thus, the present results are in line with previous findings (e.g. Pokorný, 2021a, 2021b) suggesting that online education is an appropriate alternative to traditional education. At the same time, we have to take into consideration the limits of the research which was performed at only one university and in only one course. For the objectivity, we need to state that according to the students' opinions they prefer contact teaching to online teaching. Žilková \& Žilková (2021) identified students' anxiety connected with e-testing in the same course. We consider the stress and anxiety to be a subject of further investigation. That is because the aim of mathematical and geometrical preparation for future teachers is not only to help them succeed in their course work but also to increase their levels of satisfaction.

Moawad (2020) also found that the most frequent stressor reported by students is the uncertainty regarding the end of semester, the fairness of online exams and assignments as well as their own ability to understand and comprehend the lectures. Another stress factor identified by students was related to the online submission of the exams and assignments. Moawad (2020) suggests that it is because successful course work submission is determined by the speed and strength of internet connection. Thus, when submitting online, students have to rely on external factors which elevates their stress levels. Therefore, we seek to investigate the relationship between the students' test performances and stress levels in the next stage of our research. Gopal, Singh, \& Aggarwal (2021) observed the effect of online teaching on students' performance during the COVID-19 pandemic. The results revealed four factors that had an impact on students' satisfaction: quality of lecturer, course design, prompt feedback, and student's expectations. Subsequently, students' satisfaction had a positive impact on their overall performance (Gopal, Singh, \& Aggarwal, 2021). However, in our course, we attempted to reduce the differences between in-person and remote approaches to teaching (the lecturer and the course content remained the same, students received feedback on regular basis). Thus, we believe that the students' results were comparable, and no significant differences were found between the pre-pandemic time and during the pandemic.

\section{ACKNOWLEDGEMENTS}

The study was supported by the grant VEGA 1/0592/20 Gender aspect mathematical anxiety of young school children.

\section{REFERENCES}

CIT UK (2021). Vyhodnotenie prieskumu o dištančnej výučbe v ZS 2020/2021/ pedagógovia [Evaluation of the survey on distance education in WS 2020/2021 - teachers]. Bratislava: 
Comenius University. Retrieved from https:/uniba.sk/fileadmin/ruk/cit/e-learning/Vyhodnotenie_prieskumu_ZS_2020-21_ucitelia.pdf.

CIT UK (2021). Vyhodnotenie prieskumu o dištančnej výučbe v ZS 2020/2021/ študenti [Evaluation of the survey on distance education in WS 2020/2021 - students]. Bratislava: Comenius University. Retrieved from https://uniba.sk/fileadmin/ruk/cit/e-learning/ Vyhodnotenie_prieskumu_ZS_20-21_studenti.pdf.

Gop a l, R., Sing h, V., \& A g g a r w a l, A. (2021). Impact of online classes on the satisfaction and performance of students during the pandemic period of COVID-19. Education and Information Technologies, 26. https://doi.org/10.1007/s10639-021-10523-1.

Chakraborty, P., Mit ta l, P., Gupta, M.S., Yadav, S., \& A rora, A. (2021). Opinion of students on online education during the COVID-19 pandemic. Human Behavior and Emerging Technologies, 3(3), 357-365. https://doi.org/10.1002/hbe2.240.

Chiu, Thomas, K.F. (2021). Applying the self-determination theory (SDT) to explain student engagement in online learning during the COVID-19 pandemic. Journal of Research on Technology in Education. https://doi.org/10.1080/15391523.2021.189199.

K u r u c, M., et al. (2020). Sebaregulácia učenia sa študentov predprimárneho a primárneho $v z d e l a ́ v a n i a$. [Self-regulation of learning of pre-primary and primary education students.] Bratislava: Comenius University. ISBN 978-80-223-4996-3.

Mo aw ad, R.A. (2020). Online Learning during the COVID-19 Pandemic and Academic Stress in University Students. Revista Romaneasca Pentru Educatie Multidimensionala, 12(1Sup2), 100-107. https://doi.org/10.18662/rrem/12.1sup2/252.

Obaid, A.H. \& A l-Hus sein i, K.A.O. (2019). Study the Impact of Electronic Tests Using Moodle Program on Student Achievement. Retrieved from https://www.researchgate. net/publication/336720948_Study_the_Impact_of_Electronic_Tests_Using_Moodle_ Program_on_Student_Achievement.

O p r o i u, C. (2014). A Study about Using E-learning Platform (Moodle) in University Teaching Process, Procedia - Social and Behavioral Sciences, 180 (pp. 426-432). https://doi.org/ 10.1016/j.sbspro.2015.02.140.

Pok or ný, M. (2021). E-learning in manipulative geometry teaching. Accepted on The $17^{\text {th }}$ International Scientific Conference eLearning and Software for Education. Bucharest, April 22-23, 2021. https://doi.org/10.12753/2066-026X-21-000.

Pokorný, M. (2021). Video Lessons and E-learning Can Overcome Ban of Face-to-face Lessons in Teaching Mathematics. 2021 International Symposium on Educational Technology (ISET), pp. 44-47. https://doi.org/10.1109/ISET52350.2021.00019.

Spitzer, M.W.H. \& Musslick, S. (2021). Academic performance of K-12 students in an online-learning environment for mathematics increased during the shutdown of schools in wake of the COVID-19 pandemic. PLOS ONE 16(8): e0255629. https://doi.org/10.1371/ journal.pone.0255629.

Ya d a v, A.K. (2021). Impact of Online Teaching on Students' Education and Health in India during the Pandemic of COVID-19", Coronaviruses 2021, 2(4). https://doi.org/10.2174/26 66796701999201005212801.

Žilková, K. \& Žilková, V. (2021). Perception of elementary geometry e-test from the perspective of future preservice primary teachers: a qualitative study. International Symposium Elementary Mathematics Teaching SEMT 2021. Prague: Charles University. ISBN 978-80-7603-260-6. 